\title{
Casting out myeloma kidney
}

\section{By Lev Osherovich, Senior Writer}

A team from The University of Alabama at Birmingham has proposed a new strategy to treat cast nephropathy, a common renal complication of multiple myeloma. ${ }^{1}$ The approach involves using a cyclic peptide therapeutic to block the interaction between tumor-derived immunoglobulin light chain proteins and an abundant urine protein called uromodulin. The team now needs to optimize the peptide's oral bioavailability.

Cast nephropathy, also known as myeloma kidney, causes acute kidney injury and failure in patients with MM. The condition arises from the accumulation of urinary casts, which are large aggregates of immunoglobulin light chain (IgLC) bound to uromodulin (UMOD; THP). ${ }^{2}$

In MM, "cancer cells overproduce immunoglobulins, and these can clog up the kidney," said Paul Sanders, professor of medicine, physiology and biophysics and director of the Nephrology Research and Training Center at UAB.

\section{"This is exactly the} kind of paper we look for to decide what to work on."

-Doug Treco, Ra Pharmaceuticals Inc.

In rats injected with large quantities of MM-associated IgLCs, the cyclic peptide prevented cast nephropathy, and decreased kidney damage and increased acute renal function compared with vehicle.

Results were published in The Journal of Clinical Investigation. Sanders has filed for a patent covering the cyclic peptide, and the IP is available for licensing.

Sanders hopes to move the peptide into preclinical development and is seeking an industry partner.

\section{Role of THP}

One concern is whether blocking THP's interaction with IgLC will affect renal function in the long term. The normal physiological role of THP is unknown, but the protein does bind a variety of other proteins besides IgLC and may help prevent bacterial infections in the kidney.

"There are all kinds of hypotheses about what THP does, but nothing is certain," said Sanders. Thus, he said it is hard to predict the long-term physiological effects of the cyclic peptide on renal function.

To assess the peptide's tolerability, Sanders is now conducting pharmacokinetic, pharmacodynamic and dose-ranging studies in rats. "It's a very nontoxic molecule so far," he noted.

Because THP is continually excreted in the urine, a continual block of the protein's interaction with IgLC may require frequent dosing with the antagonistic peptide.

As a result, Sanders thinks an oral formulation of the cyclic peptide would be ideal as an adjunct to chemotherapy. The team injected the peptide in the current study, but Sanders cited preliminary evidence from his lab showing that the cyclic peptide might be effective when given orally.

Doug Treco, president, CEO and cofounder of

There are no targeted therapeutics aimed at cast nephropathy, and clinicians instead have focused on reducing IgLC levels with aggressive chemotherapy. However, normalizing IgLC levels can take several months of chemotherapy, and the kidney remains vulnerable to injury during the course of treatment.

Prior work by Sanders and other researchers established that THP could bind a variety of IgLC isoforms, ${ }^{3}$ but it was not clear whether blocking the interaction could prevent kidney failure.

Now, said Sanders, "we have shown that cast nephropathy arises from the binding of immunoglobulin light chain to THP in the kidney-this presents a therapeutic opportunity."

\section{Urine trouble}

Sanders' team began by pinpointing the structural features of IgLC when bound by THP. The team used a yeast-protein interaction screening technique to identify IgLC peptide fragments with maximal binding to THP and then converged on a 12-amino-acid sequence in a conserved region of the antibody.

The team next made a cyclic version of the peptide. Cyclic peptides are more stable and potent in vitro and in vivo than their linear counterparts.

In vitro, the cyclic peptide decreased binding of full-length THP to six different IgLC variants compared with no treatment. cyclic peptide company Ra Pharmaceuticals Inc., said Sanders' study provides good proof of concept of the feasibility of targeting the THPIgLC interaction, but the team's peptide would likely have to be heavily modified to become an orally available drug.

“They've taken a sequence and shown it can interact with the same target as the originating protein. It looks like it could be an effective approach," said Treco.

He added that unmodified cyclic peptides like the one made by Sanders usually have low oral potency and are quickly degraded by digestive proteases.

Ra has a library of cyclic peptides with backbones engineered for maximal oral availability and stability. The company's lead candidate is a cyclic peptide antagonist of kallikrein that is being developed for hereditary angioedema (HAE).

Treco said THP was not yet sufficiently well validated as a target for Ra to jump into the space. He wanted to see some proof of clinical efficacy with the injected version of the peptide before deciding whether to launch an internal screening effort.

But, he added, "this is exactly the kind of paper we look for to decide what to work on."

Osherovich, L. SciBX 5(23); doi:10.1038/scibx.2012.589

Published online June 7, 2012 


\section{ANALYSIS}

\section{TARGETS \& MECHANISMS}

REFERENCES

1. Ying, W.-Z. et al. J. Clin. Invest.; published online April 9, 2012; doi:10.1172/JCl46490

Contact: Paul W. Sanders, The University of Alabama at Birmingham, Birmingham, Ala.

e-mail: psanders@uab.edu
2. Hutchison, C.A. et al. Nat. Rev. Nephrol. 8, 43-51 (2011)

3. Sanders, P.W. \& Booker, B.B. J. Clin. Invest. 89, 630-639 (1992)

COMPANIES AND INSTITUTIONS MENTIONED

Ra Pharmaceuticals Inc., Cambridge, Mass.

The University of Alabama at Birmingham, Birmingham, Ala. 